\title{
Sedimentação em leite UHT integral, semidesnatado e desnatado durante armazenamento
}

\author{
Particle sedimentation in semi-skimmed, skimmed on whole milk UHT, during storage
}

\author{
Cintia Neuwald Vesconsi ${ }^{\mathrm{I}}$ Alice Teresa Valduga ${ }^{\mathrm{I}}$ Alexandre José Cichoski ${ }^{\mathrm{I}}{ }^{*}$
}

\section{RESUMO}

Um dos maiores problemas do leite UHT é a sedimentação que ocorre durante o período de armazenamento, o que é muito reclamado pelos consumidores. O objetivo deste trabalho foi determinar a sedimentação em leite UHT integral, semidesnatado e desnatado, armazenados a $20^{\circ} \mathrm{C}$ e $30^{\circ} \mathrm{C}\left( \pm 1^{\circ} \mathrm{C}\right)$ durante 120 dias. Nos leites pasteurizados que deram origem aos leites UHT, foram efetuadas análises físico-químicas e microbiológicas (bactérias mesófilas, psicrotróficas e láticas) e, nos leites UHT integral, semidesnatado e desnatado, avaliaram-se a acidez, $p H$, fervura, sensorial, integridade das embalagens e sedimentação, logo depois de embalados e no 30, 60․ $90^{\circ}$ e $120^{\circ}$ dia de armazenamento. Os leites pasteurizados integral, semidesnatado e desnatado apresentaram resultados dentro dos padrões estipulados pela indústria para as bactérias mesófilas $\left(\log _{10}\right.$ 4,37 a $\left.\log _{10} 4,08 U F C ~ m L^{-1}\right)$, psicrotróficas $\left(\log _{10} 3,06\right.$ a $\log _{10}$ 2,77UFC $\left.\mathrm{mL}^{-1}\right)$ e lácticas $\left(\log _{10} 3,10\right.$ a $\log _{10} 2,42$ UFC $\left.\mathrm{mL}^{-1}\right)$, que diferiram significativamente $(P<0,05)$ das contagens dos leites in natura que lhes deram origem. Os valores de acidez $\left(0,15 \%\right.$ ácido láctico), crioscopia $\left(-0,535\right.$ a $\left.-0,540^{\circ} \mathrm{H}\right)$, gordura, densidade (1,031 a 1,034g $\left.\mathrm{mL}^{-1}\right)$, ESD (8,65 a 8,93\%) e pH $(6,70$ a 6,80) também ficaram dentro dos padrões. A partir do $60^{\circ}$ dia de armazenamento foi observada sedimentação nos três tipos de leites UHT a $20^{\circ} \mathrm{C}(0,80$ a $1,10 \mathrm{~g})$ e a $30^{\circ} \mathrm{C}(1,0$ a $1,40 \mathrm{~g})$.

Palavras-chave: leite, UHT, armazenamento, sedimentação, qualidade.

\section{ABSTRACT}

One of the biggest problems of UHT milk is the sedimentation of protein particles that occurs during the storage period, which faces rejection by the consumers. The aim of this study was to evaluate the particle sedimentation in semiskimmed, skimmed and wholemilk, stored at $20^{\circ} \mathrm{C}, 30^{\circ} \mathrm{C}( \pm 1)$ for 120 days. In pasteurized milk that yielded UHT milk physicochemical and microbiological analisys (mesophilic, psychrotrophic and lactic acid bacteria) were carried out. In semi-skimmed, skimmed and whole milk, the acidity, $\mathrm{pH}$, boiling, sensory analysis, integrity of packaging and sedimentation tests were carried out shortly after packing and at $30^{\text {th }}, 60^{\text {th }}, 90^{\text {th }}$ and $120^{\text {th }}$ days of storage. The pasteurized whole milk, semi skimmed and skimmed milk showed results within the required standards by the industry for mesophilic bacteria $\left(\log _{10} 4.37\right.$ a $\left.\log _{10} 4.08 U F C \mathrm{~mL}^{-1}\right)$, psychrotrophic $\left(\log _{10}\right.$ 3.06 a $\log _{10} 2.77$ UFC $\left.\mathrm{mL}^{-1}\right)$ and lactic acid $\left(\log _{10} 3.10\right.$ a $\log _{10}$ 2.42UFC $\mathrm{mL}^{-1}$ ) bacteria, that differed significantly (5\%) of value of fresh milk from which they originate. The values of acidity (0.15\% ác. láctic), freezing point $\left(-0.535\right.$ a $\left.-0.540^{\circ} \mathrm{H}\right)$, fat, density (1.031 a $\left.1.034 \mathrm{~g} \mathrm{~mL}^{-1}\right), \mathrm{pH}(6.70$ a 6.80) and degreased dry extract (8.65 a 8.93\%) also were within the standards. From the $60^{\text {th }}$ day of storage on, particle sedimentation was observed in the three types of UHT milk at the $20^{\circ} \mathrm{C}(0.80 \mathrm{a} 1.10 \mathrm{~g})$ at the $30^{\circ} \mathrm{C}(1.0 \mathrm{a} 1.40 \mathrm{~g})$.

Key words: storage, UHT milk, sedimentation, quality.

\section{INTRODUÇÃO}

A baixa qualidade microbiológica do leite cru destinado ao processamento UHT tem dificultado a qualidade deste, proporcionando diminuição na vida de prateleira e defeitos como sedimentação e gelificação, além do desenvolvimento de sabores e odores

IDepartamento de Engenharia de Alimentos, Universidade Regional Integrada (URI), Campus de Erechim, Av. Sete de Setembro, 1621, 99700-000, Erechim, RS, Brasil.

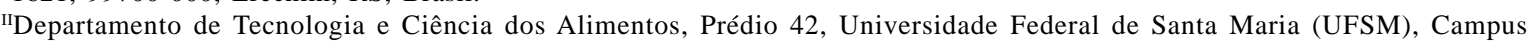
Universitário, Bairro Camobi, 97105-900, Santa Maria, RS, Brasil. E-mail: cijoale@gmail.com. *Autor para correspondência. 
desagradáveis. Essas alterações são decorrentes da ação das enzimas proteolíticas e lipolíticas de origem microbiana, que em grande parte são termoestáveis, permanecendo ativas mesmo após a esterilização (GIGANTE, 2004; VIDAL-MARTINS et al., 2005), promovendo nas proteínas as maiores alterações (CUNHA, 2001).

A proteólise no leite UHT durante o armazenamento é um exemplo de redução da estabilidade, devido à formação de sedimento, configurando assim um problema de qualidade (SANTOS, 2004). A presença de sedimentos durante a estocagem é considerada um grande problema na indústria de leite UHT, uma vez que reduz a vida de prateleira e pode ocasionar rejeição do leite UHT pelo consumidor. A sedimentação pode ser entendida como a perda da estabilidade proteica do leite submetido a tratamentos térmicos. Ocorre formação de sedimentos decorrente da alta temperatura empregada no processamento, e se deve à maior quantidade de proteínas desnaturadas e à precipitação dos sais minerais. (SILVA, 2003).

Os problemas anteriormente relatados demonstram a importância de se acompanhar o leite UHT durante seu armazenamento e também por que é de interesse das indústrias produtoras desse tipo de leite. Assim, o objetivo deste trabalho foi determinar a sedimentação em leite UHT integral, semidesnatado e desnatado, durante período de armazenamento de 120 dias a $20^{\circ} \mathrm{C}$ e $30^{\circ} \mathrm{C}\left( \pm 1^{\circ} \mathrm{C}\right)$, por serem essas as temperaturas em que os leites são armazenados quando de sua venda no território nacional.

\section{MATERIAIS E MÉTODOS}

Este trabalho foi realizado no período de janeiro a maio de 2009 em um laticínio no norte do estado do Rio Grande do Sul.

Leite cru

O leite cru dessa indústria é oriundo de 21 rotas diferentes e originou os leites pasteurizados e esterilizados deste trabalho. Decorrente do grande número de informações obtidas sobre o leite cru, elaborou-se outro trabalho científico.

Leite pasteurizado

As análises nos leites pasteurizados ocorreram logo após o término do processo, antes de serem destinados ao tratamento de esterilização.

Análises físico-químicas

Acidez titulável (método B), crioscopia, densidade, estabilidade ao etanol $80 \%$, extrato seco total (EST) e desengordurado (ESD) pelo método B (disco de Ackermann), gordura pelo método $\mathrm{C}$, e $\mathrm{pH}$ foram realizadas de acordo com metodologia descrita na Instrução Normativa 68 do MAPA(BRASIL, 2006).

Análises microbiológicas

1. Contagem total de bactérias mesófilas (CTBM): utilizou-se o equipamento eletrônico IBC Bentley e sua determinação fundamentou-se no método de citometria de fluxo, seguindo metodologia descrita no Internacional Dairy Federation standard IDF 100B (1991).

2. Contagem de Células Somáticas (CCS): foi determinada conforme o método de citometria de fluxo, seguindo metodologia descrita no Internacional Dairy Federation standard IDF 148-2 (2006).

3. Bactérias láticas: foram determinadas conforme Instrução Normativa 62 do MAPA (BRASIL, 2003) e ANTUNES (2007).

4. Bactérias psicrotróficas: foram determinadas conforme metodologia descrita na Instrução Normativa 62 do MAPA (BRASIL, 2003). Nessa determinação, utilizou-se o método rápido petrifilme $3^{\mathrm{M} \circledast}$ aprovado por Standard Methods for the Examination of Dairy Products, / APHA - American Public Health Association e MAPA - AUP n.894/2001; AOACR (Oficial Methodos of Analysis, WEHR \& FRANK, 2004).

O número de colônias encontrados nas análises microbiológicas foram expressos em $\log _{10} \mathrm{UFC}$ $\mathrm{mL}^{-1}$.

\section{Leite UHT}

As análises dos leites UHT foram realizadas logo após sua esterilização (tempo zero) e no $30^{\circ}, 60^{\circ}$, $90^{\circ}$ e $120^{\circ}$ dia de armazenamento a $20^{\circ} \mathrm{C}\left( \pm 1^{\circ} \mathrm{C}\right)$ e $30^{\circ} \mathrm{C}$ $\left( \pm 1^{\circ} \mathrm{C}\right)$.

Foram realizadas análises de $\mathrm{pH}$, crioscopia, gordura, densidade, EST e ESD e estabilidade ao etanol a $80 \%$ (estima a estabilidade térmica), conforme descritas para o leite pasteurizado, e análises específicas para leite UHT que foram:

1. Acidez Titulável conforme método A descrito na Instrução Normativa 68 do MAPA(BRASIL, 2006).

2. Fervura ou cocção: com o objetivo de avaliar a precipitação das proteínas, devido à acidez elevada, através do aquecimento do leite, seguindo metodologia descrita na Instrução Normativa 68 do MAPA(BRASIL, 2006).

3. Mesófilos aeróbios determinados conforme metodologia descrita na Instrução Normativa 62 do MAPA(BRASIL, 2003).

4. Análise sensorial: realizada por uma equipe de oito pessoas treinadas, em que se avaliou o aspecto, a cor, 
o odor e o sabor, seguindo metodologia descrita na Instrução Normativa 68 do MAPA(BRASIL, 2006). Os resultados foram expressos como característicos quando estavam de acordo com os padrões descritos na portaria 370 do MAPA(BRASIL, 1997).

5. Sedimentação: avaliada conforme metodologia descrita por SILVA (2003). Considerou-se como fraca a sedimentação até $1,00 \mathrm{~g}$; moderada de $1,01 \mathrm{~g}$ a $2,99 \mathrm{~g}$ e forte acima de 3,00g, baseado em valores definidos pela indústria.

6. Avaliação da hermeticidade da embalagem: conforme metodologia descrita TETRA PAK. Dairy processing handbook. Lund, Sweden, 1996.

Análises estatísticas

Todas as análises foram realizadas em duplicata verdadeira e calcularam-se a média, o desvio padrão, análise de variância e o teste de Tukey com $95 \%$ de confiança $(\mathrm{P}<0,05)$, empregando software Statistic versão 5.0 (USA, 1995).

\section{RESULTADOS E DISCUSSÃO}

\section{Leite cru}

Os leites crus misturados que foram utilizados na elaboração dos diferentes leites UHT, e que estavam estocados nos tanques da indústria, apresentaram as seguintes características: gordura 3,5g $100 \mathrm{~g}^{-1}( \pm 0,14)$, densidade $1,031 \mathrm{~g} \mathrm{~mL}^{-1}( \pm 0,0003)$, EST $12,31 \mathrm{~g} 100 \mathrm{~g}^{-1}( \pm 0,21)$, ESD 8,77g $100 \mathrm{~g}^{-1}( \pm 0,09)$, estabilidade ao etanol 78\%, e o pH e a acidez variaram de 6,72 a 6,79 e de $14,2^{\circ} \mathrm{D}$ a $15,4^{\circ} \mathrm{D}$. Todos esses valores ficaram de acordo com os padrões estipulados pela indústria e com a Instrução Normativa 51 (BRASIL, 2002). O número de colônias das bactérias lácticas variou de 4,04log $\mathrm{UFC} \mathrm{mL}^{-1}$ a $6,36 \log _{10} \mathrm{UFC} \mathrm{mL}^{-1}$, mesófilas de 5,61 $\log _{10} \mathrm{UFC} \mathrm{mL}^{-1}$ a $6,66 \log _{10} \mathrm{UFC} \mathrm{mL}^{-1}$, e as psicrotróficas de 4,39log $\mathrm{UFC} \mathrm{mL}_{10}^{-1}$ a 6,22 $\log _{10} \mathrm{UFC} \mathrm{mL}^{-1}$.

Leite pasteurizado

O número de colônias das bactérias mesófilas, psicrotróficas e bactérias láticas presentes no leite cru (que permaneceu 5 horas a $5^{\circ} \mathrm{C}$ nos tanques de estocagem) e dos três tipos de leites pasteurizados (com teores de gorduras padronizados) que foram utilizados na elaboração de cada tipo de leite UHT encontram-se na figura 1.

O número máximo de colônias de bactérias mesófilas aceito pela legislação em leite pasteurizado é no máximo de 4,90 $\log _{10} \mathrm{UFC} \mathrm{mL}^{-1}$, mas, para as bactérias

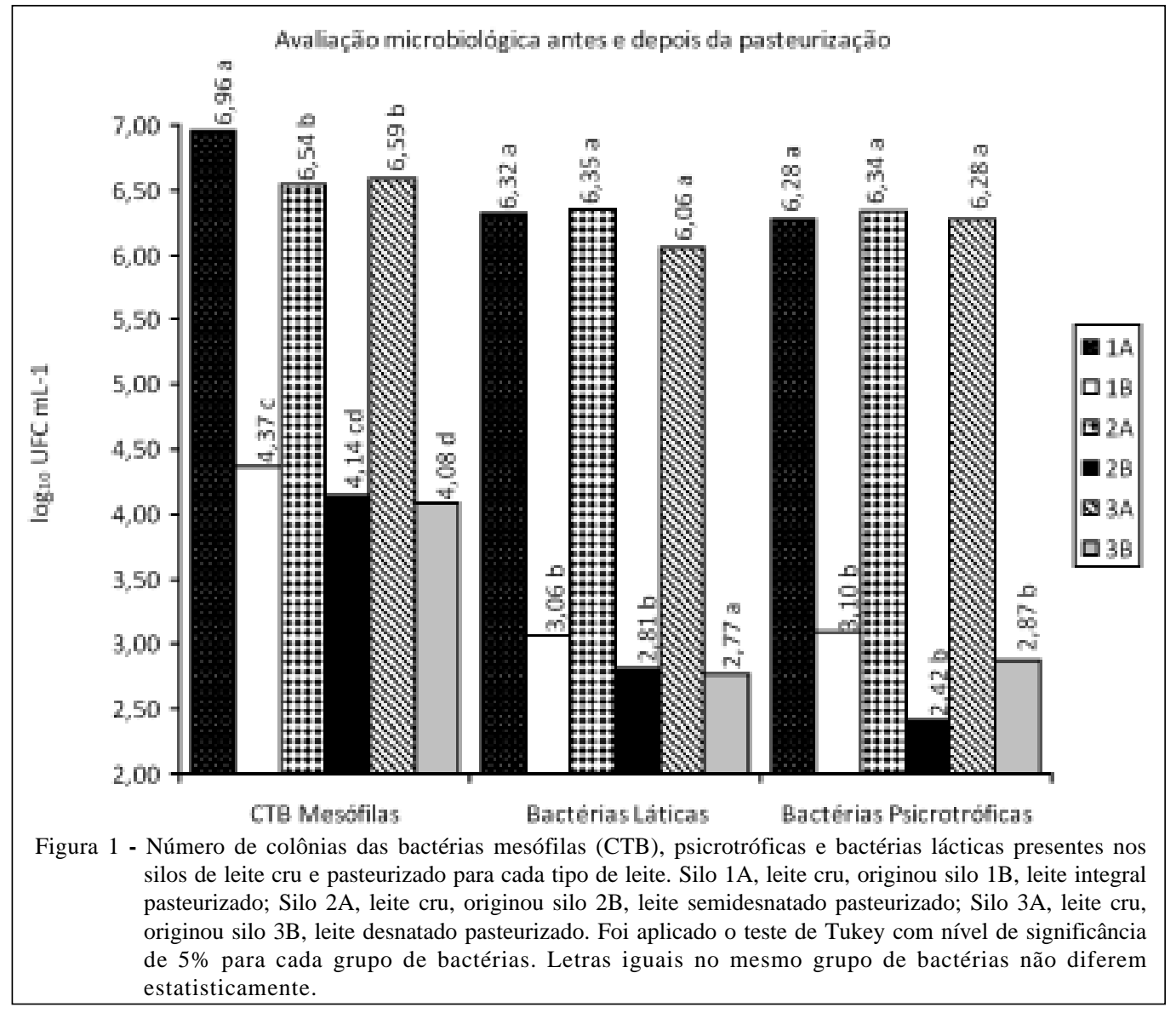

Ciência Rural, v.42, n.4, abr, 2012. 
psicrotróficas e bactérias lácticas, não existe nada definido (BRASIL, 2002). Os três tipos de leites pasteurizados apresentaram número de colônias de bactérias mesófilas dentro dos valores permitidos pela legislação (Figura 1).

A maior redução no número de colônias de bactérias psicrotróficas após a pasteurização ocorreu no leite semidesnatado e foi de $55,74 \%$, enquanto que, no leite integral e desnatado, a redução foi de 51,58\% e $54,26 \%$, respectivamente. Nas bactérias mesófilas, a redução média foi $37,33 \%$ nos três tipos de leite, e o leite desnatado apresentou a maior redução. Para as bactérias lácticas, a redução média foi de 55,59\% e a maior redução ocorreu no leite semidesnatado. Ocorreu diferença significativa $(\mathrm{P}<0,05)$ nos números de colônias de bactérias mesófilas, psicrotróficas e lácticas entre os leites crus e os três tipos de leites pasteurizados.

ZOOCHE et al. (2002) encontraram número de colônias de bactérias mesófilas e psicrotróficas de 4,00 $\log _{10}$ UFC $\mathrm{mL}^{-1}$ em leite pasteurizado desnatado. Esse número é próximo ao que foi encontrado neste trabalho para as bactérias mesófilas nos leites pasteurizados avaliados, enquanto que, para as bactérias psicrotróficas, o número foi menor, uma vez que variaram de $2,42 \log _{10} \mathrm{UFC} \mathrm{mL}^{-1}$ (leite semidesnatado) a $3,1 \log _{10} \mathrm{UFC} \mathrm{mL}^{-1}$ (leite integral, Figura 1). Ainda segundo os pesquisadores, as bactérias psicrotróficas na quantidade de $4,00 \log _{10} \mathrm{UFC}$ $\mathrm{mL}^{-1}$ podem produzir enzimas termoestáveis responsáveis pelo cheiro e sabor desagradáveis e coagulação do produto, encurtando assim a sua vida útil, lembrando que os leites crus deste trabalho apresentaram número de colônias de bactérias psicrotróficas de 6,28 a 6,34 $\log _{10} \mathrm{UFC} \mathrm{mL}^{-1}$ (Figura 1 ).

Os valores de acidez, crioscopia, gordura, densidade, ESD e pH ficaram dentro dos padrões estipulados pela indústria e pela legislação, cujos valores foram: acidez (\% ácido lático) de 0,14 a 0,18; crioscopia, máximo de $-0,530^{\circ} \mathrm{H}$, estabilidade ao etanol 72\%, ESD mínimo 8,4 \% (BRASIL, 2002). A legislação não estabelece padrões para a densidade e o $\mathrm{pH}$.

Os valores das características físicoquímicas dos três tipos de leite pasteurizados utilizados na elaboração de cada tipo de leite UHT encontram-se na tabela 1.

Os leites UHT integral e desnatado apresentaram pequena variação nos valores de crioscopia em relação ao leite pasteurizado que lhe deu origem (Tabela 1), isso estaria associado à adição de citrato de sódio. Essa substancia está presente naturalmente no leite e, em média, aparece em quantidade de $2 \mathrm{mg} \mathrm{L}^{-1}$. No processo UHT, devido aos tratamentos térmicos empregados e à homogeneização, as proteínas tendem a desestabilizar (VIDALMARTINS et al., 2005). Para estabilizá-las, a legislação permite a adição de pequena quantidade de diferentes tipos de citratos e de fosfatos de sódio, separados ou em combinação, em quantidade não superiores a $0.1 \mathrm{~g}$ 100 $\mathrm{ml}^{-1}$ (BRASIL, 1997).

\section{Leite UHT}

As amostras dos três tipos de leite UHT estudados, em todos os tempos e nas duas condições avaliadas, não apresentaram nenhum tipo de bactérias que estavam presentes no leite pasteurizado, também não apresentaram alteração na análise de estabilidade ao etanol a $80 \%(\mathrm{v} / \mathrm{v})$.

Os valores de acidez para cada tipo de leite UHT armazenados a $20^{\circ} \mathrm{C}\left( \pm 1^{\circ} \mathrm{C}\right)$ e a $30^{\circ} \mathrm{C}\left( \pm 1^{\circ} \mathrm{C}\right)$ durante 120 dias encontram-se na tabela 2.

Com exceção do leite integral que apresentou acidez de $0,20 \mathrm{~g}$ ácido lático $100 \mathrm{~mL}^{-1}$ no $120^{\circ}$ dia de armazenamento a $30^{\circ} \mathrm{C}$, os demais leites UHT analisados (integral a $20^{\circ} \mathrm{C}$, semidesnatado e desnatado a $20^{\circ}$ e a $30^{\circ} \mathrm{C}$ ) apresentaram valores de acidez dentro

Tabela 1 - Valores das características físico-químicas dos três tipos de leites pasteurizados e dos respectivos leites UHT originados logo após processamento.

\begin{tabular}{lllllll}
\hline \multirow{2}{*}{ Análises } & \multicolumn{2}{c}{ Leite Integral } & \multicolumn{2}{c}{ Leite Semidesnatado } & \multicolumn{2}{c}{ Leite Desnatado } \\
& Pasteurizado & \multicolumn{1}{c}{ UHT } & Pasteurizado & \multicolumn{1}{c}{ UHT } & Pasteurizado & \multicolumn{1}{c}{ UHT } \\
\hline Acidez (\%ácido lático) & $0,15 \pm 0,01$ & $0,16 \pm 0,01$ & $0,15 \pm 0,01$ & $0,15 \pm 0,00$ & $0,14 \pm 0,01$ & $0,15 \pm 0,01$ \\
Crioscopia $\left({ }^{\circ} \mathrm{H}\right)$ & $-0,535 \pm 0,001$ & $-0,538 \pm 0,001$ & $-0,540 \pm 0,002$ & $-0,543 \pm 0,002$ & $-0,536 \pm 0,001$ & $-0,535 \pm 0,001$ \\
pH & $6,70 \pm 0,02$ & $6,75 \pm 0,02$ & $6,80 \pm 0,01$ & $6,76 \pm 0,01$ & $6,76 \pm 0,01$ & $6,77 \pm 0,01$ \\
Gordura (\%) & 3,2 & 3,2 & 1,1 & 1,1 & 0,1 & 0,1 \\
Densidade (g·mL $\mathrm{mL}^{-1}$ ) & 1,031 & 1,031 & 1,034 & 1,034 & 1,034 & 1,035 \\
ESD (\%) & 8,65 & 8,65 & 8,93 & 8,96 & 8,78 & 9,03 \\
\hline
\end{tabular}

Nota: 1 - Os valores de gordura, densidade, Extrato Seco Desengordurado (ESD) não apresentaram desvios nas análises de duplicata realizadas. 
Tabela 2 - Valores médios de acidez, em g/100mL, de ácido lático e pH para cada tipo de leite UHT durante armazenamento de 120 dias a $20^{\circ} \mathrm{C}\left( \pm 1^{\circ} \mathrm{C}\right)$ e a $30^{\circ} \mathrm{C}\left( \pm 1^{\circ} \mathrm{C}\right)$.

\begin{tabular}{|c|c|c|c|c|c|c|}
\hline Leites & $\mathrm{T}\left({ }^{\circ} \mathrm{C}\right)$ & Zero dia & $30^{\circ}$ dia & $60^{\circ}$ dia & $90^{\underline{0}}$ dia & $120^{\circ}$ dia \\
\hline \multirow{2}{*}{ Integral } & 20 & $0,15 / 6,40$ & $0,15 / 6,68$ & $0,17 / 6,68$ & $0,17 / 6,71$ & $0,18 / 6,65$ \\
\hline & 30 & $0,15 / 6,75$ & $0,15 / 6,64$ & 0,18/6,66 & $0,18 / 6,65$ & $0,20 / 6,58$ \\
\hline \multirow{2}{*}{ Semidesnatado } & 20 & $0,15 / 6,76$ & $0,15 / 6,68$ & 0,16/6,70 & $0,16 / 6,74$ & $0,18 / 6,70$ \\
\hline & 30 & $0,15 / 6,76$ & $0,15 / 6,65$ & $0,17 / 6,67$ & $0,17 / 6,67$ & $0,18 / 6,58$ \\
\hline \multirow[b]{2}{*}{ Desnatado } & 20 & $0,14 / 6,77$ & $0,15 / 6,72$ & $0,16 / 6,72$ & $0,16 / 6,77$ & $0,16 / 6,71$ \\
\hline & 30 & $0,14 / 6,77$ & $0,15 / 6,67$ & $0,18 / 6,68$ & $0,18 / 6,70$ & $0,18 / 6,61$ \\
\hline
\end{tabular}

Nota: Os valores de acidez em ácido lático e pH não apresentaram desvios nas análises realizadas.

da faixa de acidez estabelecida pelo Padrão de Identidade e Qualidade do leite UHT, que estabelece acidez de 0,14 a 0,18 g ácido lático $100 \mathrm{~mL}^{-1}$ (BRASIL, 1997).

No $120^{\circ}$ dia, os três tipos de leites UHT apresentaram os menores valores de $\mathrm{pH}$, estando esses valores fora dos padrões estipulados pela indústria (Tabela 2). Embora os valores de $\mathrm{pH}$ do leite desnatado tenham permanecidos dentro dos padrões estipulados pela indústria, foram observados menores valores a $30^{\circ} \mathrm{C}$. A $20^{\circ} \mathrm{C}$, em todos os dias analisados, os três tipos de leite UHT apresentaram valores de $\mathrm{pH}$ dentro dos padrões estipulados pela indústria (Tabela 2), uma vez que a legislação não estabelece padrão de pH em leite UHT.

As análises sensoriais e de cocção realizadas detectaram, somente no leite desnatado, no $120^{\circ}$ dia a $30^{\circ} \mathrm{C}$, sabor levemente ácido e característica levemente alterada, nos demais dias, em ambas as temperaturas e nos três tipos de leites UHT estudados, não foi detectado nenhum outro tipo de alteração. Em relação ao fechamento das embalagens e à estabilidade ao etanol $80 \%$, em todos os dias, temperaturas e tipos de leite UHT estudados, não foi encontrado nenhum tipo de defeito.

A evolução da sedimentação durante os 120 dias de armazenamento, às temperaturas de $20^{\circ} \mathrm{C} \mathrm{e} 30^{\circ} \mathrm{C}$ $( \pm 1)$, nos leites UHT integral, semidesnatado e desnatado pode ser visualizada na figura 2 .

SANTOS (2007) estudou a qualidade do leite UHT durante a estocagem, e observou que com 30 dias havia sedimentação somente no fundo da embalagem, e que a gelificação aumentou significativamente no decorrer do período de armazenamento, indicando ação das enzimas produzidas pelos psicrotróficos. No decorrer do período de armazenamento, ocorreu aumento de sedimentação nos três tipos de leite UHT armazenados a $30^{\circ} \mathrm{C}$, e o leite integral no $120^{\circ}$ dia de armazenamento apresentou maior quantidade de sedimentação (Figura 2). Isso estaria relacionado com a ação das enzimas proteases termoestável produzidas pelas bactérias psicrotróficas, cuja ação é favorecida entre $20^{\circ} \mathrm{Ca} 25^{\circ} \mathrm{C}$ (CUNHA, 2001), lembrando que o número de colônias de bactérias psicrotróficas no leite cru (utilizado para elaboração dos leites UHT) variou de 6,28 a $6,34 \log _{10}$ UFC $\mathrm{mL}^{-1}$ (Figura 1), e conforme ZOCHE et al. (2002) o número de colônias de $4,00 \log _{10}$ UFC $\mathrm{mL}^{-1}$ de bactérias psicrotróficas produziriam enzimas termoestáveis. SILVA (2003) e VIDAL MARTINS et al. (2005) concluíram que o número elevado de bactérias psicrotróficas e de células somáticas no leite cru foram fatores determinantes na ocorrência de gelificação e de sedimentação em leite UHT.

\section{CONCLUSÃO}

Os leites UHT integral, semidesnatado e desnatado, armazenados a $20^{\circ} \mathrm{C}$ e a $30^{\circ} \mathrm{C}$ apresentaram sedimentação durante o período estudado. Essa sedimentação estaria relacionada com a baixa qualidade microbiológica apresentada por alguns dos leites crus recebidos pela indústria, uma vez que apresentaram número de colônias de bactérias psicotróficas superiores a $4,0 \log _{10} \mathrm{UFC} \mathrm{mL}^{-1}$. Essas bactérias produzem enzimas proteases e lípases termoestáveis, que agem sobre as proteínas favorecendo a sedimentação. As ações dessas enzimas ocorrem nas temperaturas empregadas no armazenamento desse trabalho. Com isso, sugere-se à indústria que oriente seus produtores a resfriarem rapidamente e homogeneamente o leite ordenhado. 


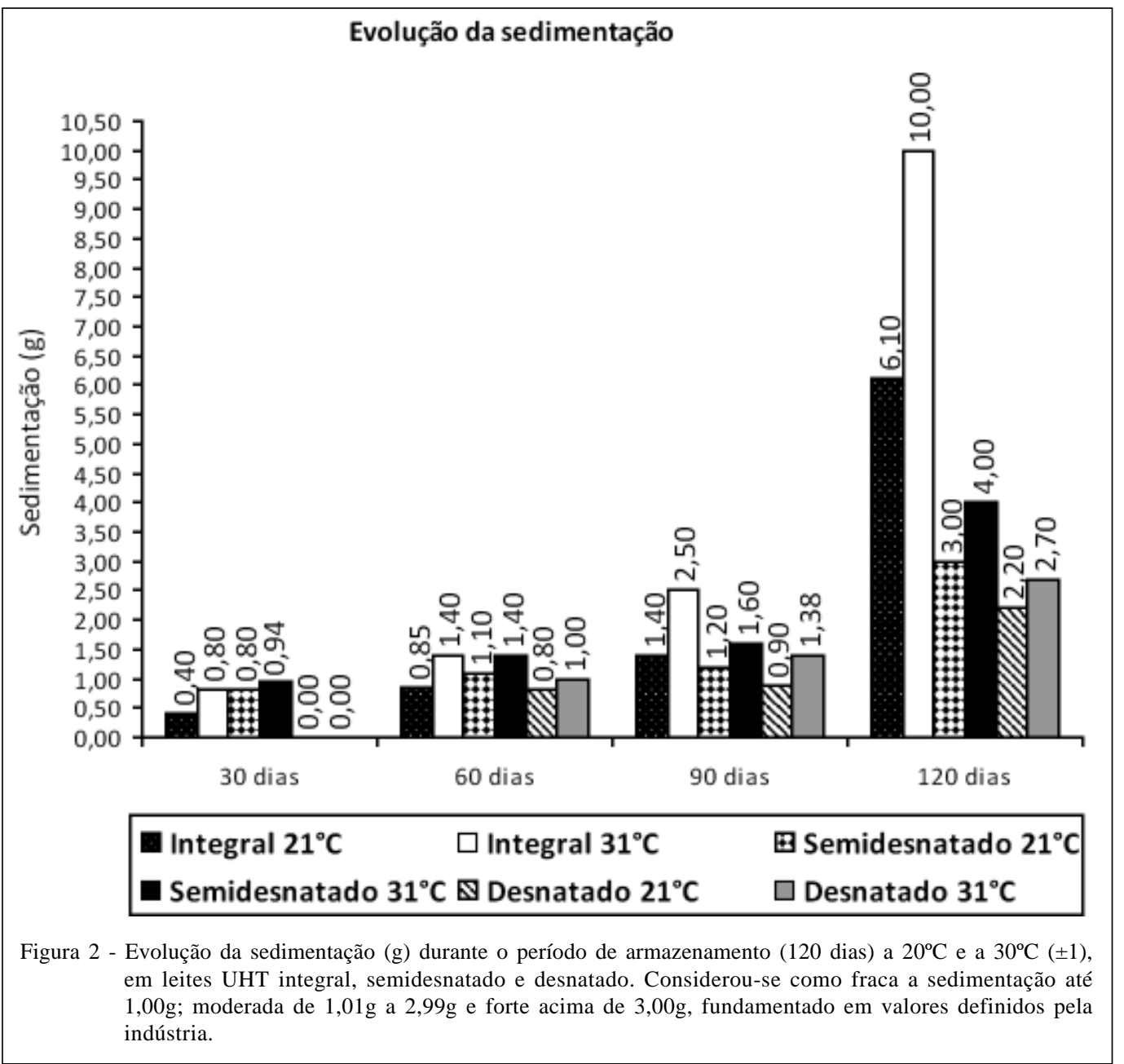

\section{REFERÊNCIAS}

ANTUNES, A.E.C. et al. Desenvolvimento de buttermilk probiótico. Ciência e Tecnologia de Alimentos, v.27, n.1, p.83-87, 2007.

BRASIL. Instrução Normativa n. 62, de 26 de agosto de 2003. Diário Oficial da República Federativa do Brasil, Brasília, p.17, 18 set. 2003. Seção I.

BRASIL. Instrução Normativa n. 68, de 12 de dezembro de 2006. Diário Oficial da República Federativa do Brasil, Brasília, p.08, 14 dez. 2006. Seção I.

BRASIL. Portaria n.370, de 04 de setembro de 1997. Regulamento técnico para fixação de identidade e qualidade de leite UHT. Diário Oficial da República Federativa do Brasil, Brasília, n.172, 08 set. 1997. Seção I.

BRASIL. Instrução Normativa n. 51, de 18 de setembro de 2002. Diário Oficial da República Federativa do Brasil, Brasília, n.172, p.13-22, 20 set. 2002. Seção I.
CUNHA, M.F. Leite UHT e o fenômeno de gelatinização. Boletin do CEPPA, v.19, n.2, p.341-352, 2001.

GIGANTE, M.L. Importância da qualidade do leite no processamento de produtos lácteos. $\mathrm{O}$ compromisso com a qualidade do leite no Brasil. Passo Fundo, RS: UPF, 2004. 331p.

INTERNATIONAL DAIRY FEDERATION (FIL-IDF). Wole Milk - Enumeration of somatic cells. Guidance on the operation of fluoro-opto-eletronic counters. Brussels, Belgium, 2006. (FIL-IDF. Doc 148-2, p.20)

INTERNATIONAL DAIRY FEDERATION (FIL-IDF). Milk and milk products enumeration of microorganisms colony count technique at $30^{\circ} \mathrm{C}$. Brussels, Belgium, 1991 . (FIL-IDF. Doc 100-B, p.3)

SANTOS, M.G. et al. Avaliação da qualidade do leite UHT durante sua vida de prateleira. In: CONGRESSO NACIONAL DE LATICÍNIOS, 24., 2007, Juiz de Fora, MG. Anais... Juiz de Fora: EPAMIG, 2007. V.62, n.357, p.141-147. 
SANTOS, M.V. Aspectos não microbiológicos afetando a qualidade do leite. O compromisso com a qualidade do leite no Brasil. Passo Fundo, RS: UPF, 2004. 331p.

SILVA, P.H.F. Leite UHT: fatores determinantes para a sedimentação e gelificação. 2003. 147f. Tese (Doutorado em Ciência dos Alimentos) - UFLA, Lavras, MG.

TETRA PAK. Dairy processing handbook. Lund, Sweden, 1996. 1 CD-ROM.

VIDAL-MARTINS, A.M. et al. Evolução do índice proteolítico e do comportamento reológico durante a vida de prateleira de leite UAT/UHT. Ciência e Tecnologia de Alimentos, v.25, n.4, p.698-704, 2005.

WERHR, H.H., FRANK, J.F. Microbiological count methods. In: Standard Methods for the examination of dairy products. 17.ed. Washington: American Public Health Association, 2004. Chapt.6, p.153-186.

ZOCCHE, F. et al. Qualidade microbiológica e físico-química do leite pasteurizado produzido na região oeste do Paraná. Archives of Veterinary Science v.7, n.2, p.59-67, 2002. 